\title{
A EXTINÇÃO DO CONDOMíNIO EDILíCIO - REVENDO O FILME "AQUARIUS"
}

\author{
Luciano de Souza Godoy*
}

Com alegria, aceitei o convite da professora Giselda Maria Fernandes Novaes Hironaka para participar do livro comemorativo do Encontro dos Grupos de Pesquisa do IBDCivil; Sobram competência e dedicação aos coordenadores e integrantes dos grupos de estudo em Direito Civil, sempre inovando e colaborando ao avanço científico da área.

Para a ocasião, escolhi debater o direito à propriedade, minha área de interesse e pesquisa, com o auxílio de um filme nacional muito destacado e recente. Acredito que arte e o ensino e a reflexão do direito podem caminhar lado a lado. Por isso, o presente artigo trata do tema do filme Aquarius.

O drama foi o único filme latinoamericano indicado à Palma de Ouro no festival de Cannes em 2016. Concentra-se na resistência da personagem principal em manter sua moradia em seu apartamento, único ainda ocupado em um prédio vazio; o roteiro do filme apresenta uma situação peculiar que deve ser melhor estudada no direito civil, em especial no direito da propriedade. Em um momento de expansão imobiliária e renovação de antigas políticas urbanas, é necessário analisar a implicação da extinção do condomínio em casos singulares como o retratado.

Dirigido por Kleber Mendonça Filho e protagonizado por Sônia Braga, o filme retrata a busca da empreiteira "Bonfim Engenharia" para adquirir um único

Formado em Direito pela USP (1991), Mestrado (1997) e Doutorado (2002) também pela USP na área de Direito Civil. Atualmente é advogado e sócio do PVG - Perlman, Vidigal e Godoy Advogados com atuação no contencioso e arbitragens. É professor da Escola de Direito de São Paulo da Fundação Getúlio Vargas nos cursos de graduação e mestrado. 
apartamento que não lhe pertence no edifício Aquarius, situado na praia de Boa Viagem, em Recife. A construção de um novo empreendimento imobiliário no terreno é o plano da empresa construtora; por óbvio, envolve a demolição do prédio e a mudança da única moradora ainda resistente. Clara, a proprietária da unidade, apesar das ofertas de alto valor, não tem a pretensão de vender seu imóvel.

A conexão da personagem principal com seu apartamento é revelada logo nas primeiras cenas. $\mathrm{O}$ apartamento - que pertenceu a uma tia já falecida - guarda as memórias afetivas de toda uma vida: a convivência com seu finado marido, o crescimento de seus filhos e comemorações familiares. Em tempos de mídias digitais e armazenamento em nuvem, a estante de Clara repleta de discos de vinil anuncia sua resistência ao processo de modernização, o qual ela considera impessoal e superficial. É nítido o direito de moradia individual da protagonista, que surge como um elemento necessário à proteção da dignidade da pessoa humana e também como componente do direito da personalidade ${ }^{1}$.

Contrapõe-se a este direito individual de moradia de Clara, a visão por um direito de moradia mais amplo, à medida que o projeto apresentado pela construtora é destinado à incorporação de um edifício com maior capacidade habitacional. Além disso, a realização dessa obra implica a concretização do direito urbanístico da região devido à possibilidade de interferência do poder público na ocupação do solo urbano e no desenvolvimento da cidade.

Se a arte imita a vida, ou a vida imita a arte não se sabe. Certo é que há concretamente um caso semelhante ao caso de Clara no filme Aquarius - com a situação vivida em um antigo prédio de apartamentos na cidade de São Paulo. O edifício Peixoto Gomide, situado na esquina da rua de mesmo nome com a rua Oscar Freire, uma das regiões com metro quadrado mais caras de São Paulo e onde ocorre uma situação peculiar. Com sete de suas nove unidades autônomas vendidas para Construtora Santa Alice, o condômino edilício também não pode ser extinto para permitir a construção de um novo empreendimento.

Em atitude semelhante à de Clara, proprietários das duas unidades autônomas se recusam a vender seus apartamentos. Os demais apartamentos, adquiridos pela construtora em 2004, encontravam-se desocupados. Em 2007, um grupo de sem-teto mudou-se para lá. Segundo os proprietários dos dois apartamentos ainda habitados, teria sido a própria Empresa Santa Alice a responsável por incitar a ocupação dos imóveis desocupados, para pressioná-los a vender seus

1 GODOY, Luciano de Souza. O direito à moradia e o contrato de mútuo imobiliário. Rio de Janeiro: Renovar, 2006, p. 37-56. 
apartamentos ${ }^{2}$. No filme, Clara também é intimidada pela construtora que, diante de sua recusa em aceitar diversas propostas de compra, passa a utilizar-se de artimanhas para tornar a habitação do edifício insustentável.

E provavelmente muitos outros casos virão. As grandes cidades brasileiras como São Paulo e Rio de Janeiro - possuem inúmeros edifícios ocupando terrenos que poderiam ser destinados a construçoes mais modernas, eficientes e com maior adequação urbanística e arquitetônica. Faltam terrenos, sobram prédios antigos e ultrapassados nas cidades grandes.

De fato, a política urbana tem uma grande importância nos dias atuais. Os processos de industrialização e urbanização, intensificados no século XX em nosso país, causaram ocupação desordenada das cidades. Como forma de conter impactos negativos do processo de urbanização, surge o direito urbanístico, que oferece mecanismos jurídicos ao Poder Público para organizar os espaços habitáveis na cidade. É compreensível que a política urbana, vez ou outra, traga uma oposição entre os interesses públicos e privados. Dessa forma, minha visão - a finalidade urbanística pode interferir no direito de propriedade.

A esse respeito, nota-se que a Constituição Federal de 1988 tratou de fornecer as primeiras bases do direito urbanístico no ordenamento jurídico brasileiro. $\mathrm{O}$ art. $182^{3}$ do texto constitucional refere-se à política de desenvolvimento urbano, de

2 Disponível em: <https://wwwl.folha.uol.com.br/cotidiano/2017/07/1901712-estrangeiros-na-oscar-freire-sem-teto-terao-que-deixar-predio-invadido.shtml>. Acesso: 10/07/2018.

3 Art. 182. A política de desenvolvimento urbano, executada pelo Poder Público municipal, conforme diretrizes gerais fixadas em lei, tem por objetivo ordenar o pleno desenvolvimento das funções sociais da cidade e garantir o bem- estar de seus habitantes.

$\$ 1^{\circ} \mathrm{O}$ plano diretor, aprovado pela Câmara Municipal, obrigatório para cidades com mais de vinte mil habitantes, é o instrumento básico da política de desenvolvimento e de expansão urbana. $\$ 2^{\circ}$ A propriedade urbana cumpre sua função social quando atende às exigências fundamentais de ordenação da cidade expressas no plano diretor.

$\$ 3^{\circ}$ As desapropriaçôes de imóveis urbanos serão feitas com prévia e justa indenização em dinheiro.

$\$ 4^{\circ}$ É facultado ao Poder Público municipal, mediante lei específica para área incluída no plano diretor, exigir, nos termos da lei federal, do proprietário do solo urbano não edificado, subutilizado ou não utilizado, que promova seu adequado aproveitamento, sob pena, sucessivamente, de: I - parcelamento ou edificação compulsórios;

II - imposto sobre a propriedade predial e territorial urbana progressivo no tempo;

III - desapropriação com pagamento mediante títulos da dívida pública de emissão previamente aprovada pelo Senado Federal, com prazo de resgate de até dez anos, em parcelas anuais, iguais e sucessivas, assegurados o valor real da indenização e os juros legais. 
competência do Município. $\mathrm{O}$ instrumento base para a definição de uma política urbanística é o Plano Diretor, que deverá ser aprovado pela Câmara Municipal. A principal motivação para a existência de um instrumento como tal é direcionar o desenvolvimento da cidade para o atendimento das necessidades coletivas de toda a população.

Outrossim, à medida que um planejamento urbanístico é colocado em prática, deve-se levar respeitar e priorizar a realização de um outro direito constitucionalmente previsto: o direito à moradia. Incluído no art. $6^{\circ}$ da Constituição Federal de $1988^{4}$ entre os direitos sociais, o direito à moradia apresenta uma dualidade particular. Se, por um lado, ele constitui uma norma constitucional programática destinada a promover a todos os cidadãos brasileiros o acesso à moradia. Ele também representa, no âmbito do direito civil, um direito da personalidade decorrente da proteção à dignidade da pessoa humana.

Bom dizer e enfatizar um ponto. A reafirmação da importância da modernização dos centros urbanos por meio da construção de novos prédios com finalidades urbanísticas e habitacionais modernas - pretendida aqui - não ignora a possibilidade de existência de valor histórico de alguma dos antigos edifícios e construçōes 5 . Se assim for, há que ser identificado e preservado. Como se sabe, existem instrumentos jurídicos destinados à conservação de edifícios importantes para o Patrimônio Histórico, Cultural, Artístico e Arquitetônico nacional, quer por seu excepcional valor arqueológico ou etnográfico, bibliográfico ou artístico. Nesse sentido, há órgãos destinados a avaliar a viabilidade de tombamento de determinadas edificaçōes ${ }^{6}$ nas três esferas de Governo, o que deverá ocorrer com base no Decreto-lei n. 25, de 30 de novembro de 1937.

No caso da subutilização dos condomínios edilícios com condôminos resis-

4 Alteração realizada pela Emenda Constitucional n. 26, de 14.2.200. Disponível em: <http:// www.planalto.gov. br/ccivil_03/constituicao/emendas/emc/emc26.htm>. Acesso em: 12 julho 2018

5 O episódio da manobra política intentada pelo ex-ministro Geddel Vieira Lima, em 2016, demonstra a importância de uma avaliação dos órgãos de preservação do patrimônio histórico, cultural e ambiental livre de pressões políticas. Disponível em: <https://wwwl.folha.uol.com. br/poder/2016/11/1836516-empresa-responsavel-por-edificio-omite-contrato-de-geddel-vieira-lima.shtml>. Acesso em: 30 julho 2018.

6 Na esfera federal, temos o Instituto do Patrimônio Histórico e Artístico Nacional (IPHAN), no Estado de São Paulo contamos com o Conselho de Defesa do Patrimônio Histórico, Artístico, Arqueológico e Turístico do Estado de São Paulo (CONDEPHAAT) e, para o município de São Paulo, o Conselho Municipal de Preservação do Patrimônio Histórico, Cultural e Ambiental do Município de São Paulo (CONRESP). 
tentes à sua extinção ou à sua alienação, quando não há patrimônio histórico ou artístico a ser resguardado, existe afronta aos interesses urbanísticos. Isso ocorre porque a utilização irracional de espaços em regiōes tão importantes para a cidade reflete, precisamente, no aumento do preço dos imóveis da região, impedindo a concretização do direito à moradia. Nota-se, ainda, o afastamento das camadas mais populares de locais de fácil acesso e criando os chamados "bolsões da pobreza”. Por isso, é prejudicial à coletividade que um único apartamento ocupado em um prédio com várias unidades autônomas impeça a construção de um empreendimento com maior capacidade habitacional.

O ponto central é - a legislação hoje não atende de forma adequada a uma necessidade - um único proprietário de uma unidade em um edifício não pode obstar o desenvolvimento urbanístico da cidade, a construção de um novo prédio no terreno de um antigo que será demolido. Em termos jurídicos, Clara em Aquarius está certa, a Empresa Bonfim está errada, entretanto a legislação precisa mudar em benefício do crescimento e desenvolvimento ordenado das nossas cidades.

No que se refere à legislação do condomínio edilício, o ordenamento brasileiro ainda se revela um tanto quanto fechado às possibilidades de interferência na esfera de liberdade do particular com base no princípio da função social da propriedade ou da necessidade de implementação de uma política urbana. As normas destinadas a regular a propriedade horizontal no direito pátrio são relativamente novas, o que se deve ao recente processo de urbanização brasileiro. Dessa forma, o Código Civil de 1.916 foi omisso em relação ao tema, tratando somente do condomínio tradicional, fruto da existência de mais de um titular da propriedade de um mesmo bem.

Muito embora se tenha notícias da existência de edificações contendo propriedades distintas em um mesmo terreno com divisão por pavimentos desde a Roma Antiga, foi somente com o início da urbanização brasileira, que este tipo de moradia se popularizou no Brasil. Com isso, surgem os primeiros litígios edificações de pavimentos sobrepostos de mais de um proprietário. Diante da lacuna legislativa existente e do acelerado movimento de êxodo rural, o Congresso Nacional emite, em 1928, o Decreto Decreto-Lei n. 5.4817, que passa a regular a matéria. Nos anos seguintes, o decreto sofreu diversas modificações, visando adequar seu conteúdo à realidade social de cada momento histórico.

Para sanar a incompletude do decreto e pacificar o assunto, a Lei n. 4.591, de

7 Disponível em: <http://www2.camara.leg.br/legin/fed/decret/1920-1929/decreto-5481-25-junho-1928-776630-publicacaooriginal-140611-pl.html>. Acesso: 10 julho 2018. 
$1964^{8}$, com anteprojeto de Caio Mário da Silva Pereira, tratou do tema de maneira satisfatória à época. Denominada Lei de Condomínio e Incorporaçôes, o novo diploma legal tratou de duas matérias diversas. A abordagem de diferentes temas em uma mesma lei pode ser explicada pela necessidade de proteção de consumidores atingidos pela multiplicidade de ofertas de empreendimentos de imobiliários não finalizados, tal qual a premência de atualizar a regulação do condomínio à complexidade social.

No que diz respeito à extinção do condomínio, ora discutido neste artigo, esta lei possui dispositivos que permitem a extinção do condomínio em situações excepcionais. Os artigos 13 a 18 da Lei n. 4.591/1964 tratam das possibilidades de demolição, reconstrução e até venda do edifício por deliberação da maioria. $\mathrm{O}$ artigo $17^{9}$, alterado pela Lei n. 6.709, de 1979, apresenta, inclusive, a possibilidade de alienação total do edifício, mesmo contra a vontade de uma minoria, quando houvesse "condenação da edificação pela autoridade pública, ou ameaça de ruína", além de "motivos urbanísticos ou arquitetônicos", e também quando se constatasse "desgaste, pela ação do tempo, das unidades habitacionais".

Nesse sentido, a aplicação parte final deste dispositivo tornaria possível a extinção de condomínio com a venda da totalidade de suas unidades autônomas, possibilitando a construção de edificações que atendam uma política urbana mais racional. Prédios - como o edifício Aquarius ou o Peixoto Gomide - poderiam ser

8 Disponível em: <http://www.planalto.gov. br/ccivil_03/Leis/L4591.htm>. Acesso: 10/07/2018.

9 Art. 17. Os condôminos que representem, pelo menos 2/3 (dois terços) do total de unidades isoladas e frações ideais correspondentes a $80 \%$ (oitenta por cento) do terreno e coisas comuns poderão decidir sobre a demolição e reconstrução do prédio, ou sua alienação, por motivos urbanísticos ou arquitetônicos, ou, ainda, no caso de condenação do edifício pela autoridade pública, em razão de sua insegurança ou insalubridade. (Redação dada pela Lei n. 6.709, de 31.10.1979) $\$ 1^{\circ} \mathrm{A}$ minoria não fica obrigada a contribuir para as obras, mas assegura-se à maioria o direito de adquirir as partes dos dissidentes, mediante avaliação judicial, aplicando-se o processo previsto no art. 15. (Redação dada pela Lei n. 6.709, de 31.10.1979)

$\$ 2^{\circ}$ Ocorrendo desgaste, pela ação do tempo, das unidades habitacionais de uma edificação, que deprecie seu valor unitário em relação ao valor global do terreno onde se acha construída, os condôminos, pelo quórum mínimo de votos que representem $2 / 3$ (dois terços) das unidades isoladas e frações ideais correspondentes a $80 \%$ (oitenta por cento) do terreno e coisas comuns, poderão decidir por sua alienação total, procedendo-se em relação à minoria na forma estabelecida no art. 15, e seus parágrafos, desta Lei. (Redação dada pela Lei n. 6.709, de 31.10.1979) $\$ 3^{\circ}$ Decidida por maioria a alienação do prédio, o valor atribuído à quota dos condôminos vencidos será correspondente ao preço efetivo, e, no mínimo, à avaliação prevista no $₫ 2^{\circ} \mathrm{ou}$, a critério desses, a imóvel localizado em área próxima ou adjacente com a mesma área útil de construção. (Redação dada pela Lei n. 6.709, de 31.10.1979) 
alienados apesar da recusa de uma minoria de condôminos em vender seus apartamentos. Isso porque um projeto condizente com a lei de zoneamento urbano e com o plano diretor da cidade justifica as finalidades urbanísticas ou arquitetônicas, além de conferir ao antigo proprietário uma indenização equivalente à avaliação judicial do imóvel ou ao valor arbitrado de acordo com o preço de imóveis situados em mesma área.

Em 2008, no estado de Nova York, nos Estados Unidos, uma lei denominada "Common Interest Ownership Act" tornou possível a extinção de um condomínio após receber $80 \%$ de votos dos condôminos favoráveis à proposta de alienação ${ }^{10}$. Das 120 unidades autônomas do condomínio Parker Place, 98 já haviam sido vendidas para uma companhia privada, que optou pela demolição do mesmo. Os condôminos vencidos, por sua vez, deverão receber indenização pelo preço de suas unidades autônomas. Segundo os compradores, a proposta de transformar o prédio residencial em prédio com propriedades de aluguel deve transformá-lo em um prédio com maior ocupação e rentabilidade.

As crescentes evoluções sociais no Brasil do século XX culminaram na necessidade de adaptação das normas relativas ao condomínio edilício presentes na Lei de Condomínio e Incorporações. Como forma de preencher as lacunas legislativas decorrentes destas transformações, o Código Civil de 2.002 trouxe alteraçōes para a matéria dos condomínios edilícios para modernizar a matéria e incluir a concepção de inspiração social dos institutos tradicionalmente civis. Consequentemente, as normas trazidas entre os artigos 1.331 a 1.358 do Código Civil de 2002 revogaram tacitamente o título I, artigos $1^{\circ}$ a 27 da Lei n. 4.591/64 $4^{11}$. Até se poderia abrir uma discussão se aqueles artigos mencionados - artigo 17 complementado pelo artigo 15 - não haveriam sido revogados porque o tema não foi tratado na nova norma - Código Civil. Mas o ambiente de insegurança jurídica não é adequado para um investimento imobiliário que exige um marco legal estável.

Especificamente sobre a possibilidade de alteração da destinação do condomínio ou de sua extinção, a nova lei não contribui para a concretização de política urbana eficiente. O artigo $1.351^{12}$, do Código Civil versa que: "Depende da apro-

10 Disponível em: <https://www.nytimes.com/2008/09/28/realestate/28wczo.html>. Acesso em: 13 julho 2018.

11 VENOSA, Sílvio de Salvo. Código civil comentado: direito das coisas, posse, direitos reais, propriedade, artigos 1.196 a 1368, volume XII, p. 450. São Paulo: Atlas, 2003.

12 Art. 1.351. Depende da aprovação de $2 / 3$ (dois terços) dos votos dos condôminos a alteração da convenção; a mudança da destinação do edifício, ou da unidade imobiliária, depende da aprovação pela unanimidade dos condôminos. (Redação dada pela Lei n. 10.931, de 2004). 
vação de $2 / 3$ (dois terços) dos votos dos condôminos a alteração da convenção; a mudança da destinação do edifício, ou da unidade imobiliária, depende da aprovação pela unanimidade dos condôminos".

A necessidade de garantir a unanimidade de votos para realizar essa alteração causa inúmeros problemas para os condôminos e também para a população ${ }^{13}$. $\mathrm{Na}$ cidade de São Paulo, por exemplo, prédios utilizados como residenciais na região central, entre as décadas de 60 e 70, estão abandonados ou ocupados por movimentos de moradia, diante da impossibilidade de destiná-los para uso comercial. A não utilização desses prédios, resultado da não consolidação de uma política urbanística inclusiva e transformadora, resulta no abandono dos mesmos.

A falta de manutenção dos prédios abandonados não causa somente prejuízos monetários aos proprietários, como também permite a ocupação irregular desses edifícios, o que pode culminar em tragédias ${ }^{14}$. Nesse sentido, é dever do poder público atuar, por meio de mecanismos de direito urbanístico, visando a recuperação de edifícios degradados, abandonados ou de obras paralisadas pela justiça para viabilizar a recuperação dos mesmos e da utilização racional do espaço urbano.

É justamente este o caso do edifício Peixoto Gomide, situado nos Jardins, cujo proprietário da maioria das unidades autônomas não pode utilizar sua propriedade para os propósitos inicialmente almejados, em razão de impedimentos legais. Isso ocorre, pois, muito embora existisse a previsão legal para a venda total de um edifício em condomínio mesmo contra a vontade de uma minoria de condôminos no art. 17 da Lei n. 4.591/64, o referido dispositivo foi aparentemente revogado pelo Novo Código Civil.

Caso fosse aplicável ao caso concreto, seria a primeira demolição voluntária de um prédio com a extinção de condomínio para permitir incorporação de um novo edifício no Brasil tendo em vista objetivos urbanísticos ou arquitetônicos. Essa medida, por atender objetivos constitucionais de concretização de política urbana adequada e de acesso à moradia, representaria um salto de racionalidade para prevenir reflexos negativos do processo de expansão acelerada de grandes centros urbanos.

Ademais, a exigência de unanimidade para deliberações com conteúdo terminativo do condomínio se mostra exagerada e não razoável quando comparada com

13 Carlos Alberto Dabus Maluf afirma que há um exagero na exigência de quóruns especiais, à medida que nem a votação de emendas constitucionais exige a unanimidade para sua aprovação, in: Código Civil comentado coordenado por Regina Beatriz Tavares da Silva, 8. ed, São Paulo: Saraiva, 2012.

14 Leia mais em: <https:/wwwl.folha.uol.com.br/colunas/claudiobernardes/2018/05/uso-pontual-de-edificios-vazios-pode-melhorar-sua-imagem-e-a-da-vizinhanca.shtml>. Acesso em: $12 / 07 / 2018$. 
aquela imposta para extinguir o condomínio edilício com base no artigo $1.357^{15}$ do referido diploma legal. Este dispositivo autoriza a extinção ou venda total do condomínio, com concordância de metade mais uma das frações ideais, quando houver destruição ou ameaça de ruína. No filme Aquarius, observa-se uma possibilidade de invocação deste dispositivo, à medida que a construtora decide acondicionar madeira infestada de cupins nas unidades de sua propriedade, o que pode colocar em risco a estrutura do prédio.

Para conclusão - o direito civil como mecanismo voltado para a regulação da vida em sociedade, novamente se revela insuficiente para mediar as complexas relações da vida moderna em grandes cidades. A má utilização de espaços urbanos habitáveis em cidades de grandes dimensões como São Paulo - demonstra a todos mais uma vez a insuficiência da nossa legislação e a necessidade de se pensar em soluções para esses problemas.

Cabe ao legislador abandonar a resistência quase utópica de Clara e encarar as novas interferências ao direito de propriedade à luz da função social da propriedade e do direito urbanístico, proporcionando para os cidadãos uma cidade adaptada às necessidades atuais. Por isso, levando em consideração o direito à moradia, a propriedade e sua função social, deve-se possibilitar a extinção do condomínio por alienação apesar da resistência da minoria dos condôminos, aplicando-se indenização equivalente a seu preço de mercado. ${ }^{16}$

\section{REFERÊNCIAS}

FACHIN, Luiz Edson. Comentários ao Código Civil: parte especial: direito das coisas, vol. 15 (arts. 1.277 a 1.368). Antônio Junqueira de Azevedo (Coord.). São Paulo: Saraiva, 2003.

GODOY, Luciano de Souza. O direito à moradia e o contrato de mútuo imobiliário. Rio de Janeiro: Renovar, 2006.

KOJRANSKI, Nelson. Condominio edilício: aspectos jurídicos relevantes. 2. ed. São Paulo: Malheiros, 2015.

15 Art. 1.357. Se a edificação for total ou consideravelmente destruída, ou ameace ruína, os condôminos deliberarão em assembleia sobre a reconstrução, ou venda, por votos que representem metade mais uma das frações ideais.

$\$ 1^{\circ}$ Deliberada a reconstrução, poderá o condômino eximir-se do pagamento das despesas respectivas, alienando os seus direitos a outros condôminos, mediante avaliação judicial.

$\$ 2^{\circ}$ Realizada a venda, em que se preferirá, em condições iguais de oferta, o condômino ao estranho, será repartido o apurado entre os condôminos, proporcionalmente ao valor das suas unidades imobiliárias.

16 As pesquisas e finalizaçōes do texto contaram com a colaboração indispensável da pesquisadora Ana Clara Tonhá Xavier. 
•• Direito Civil: Estudos | Coletânea do XV Encontro dos Grupos de Pesquisa - IBDCivil

MALUF, Carlos Alberto Dabus. Condominio edilício. 3. ed. reformulada. São Paulo: Saraiva, 2009.

PEREIRA, Caio Mário da Silva. Condomínio e Incorporaçôes. 4. ed. atualizada segundo a legislação vigente. Rio de Janeiro: Forense, 1983.

TAVARES DA SILVA, Regina Beatriz et al. Código Civil comentado. 8. ed. coord. Regina Beatriz Tavares da Silva. São Paulo: Saraiva, 2012.

VENOSA, Ślvio de Salvo. Código Civil comentado: direito das coisas, posse, direitos reais, propriedade, artigos 1.196 a 1368. São Paulo: Atlas, 2003. v. XII. 